\title{
A Simplified Matrix Analysis Approach to Multi-story Buildings Involving a Friction Damper
}

\author{
Kamyar Gharra ${ }^{1}$, Karen Khanlari ${ }^{1 *}$, Jafar Asgari Marnani ${ }^{1}$ \\ ${ }^{1}$ Department of Civil Engineering, Faculty of Technology and Engineering, Central Tehran Branch, Islamic Azad University, 146966919, \\ Tehran, Iran \\ * Corresponding author, e-mail: kar.khanlari@iauctb.ac.ir
}

Received: 14 May 2021, Accepted: 16 September 2021, Published online: 22 September 2021

\begin{abstract}
Damping through friction tends to be one of the most efficient methods to suppress damage to structures from earthquakes. Realizing robust structures is therefore highly dependent on designing for the dynamic forces of friction-damped structures and exploring their reliability against natural disasters. This paper presents a simplified matrix analysis algorithm for multi-story friction- damped buildings. The behavior of friction-damped systems has analyzed more accurately by modeling the master-slave degree of freedom of the joints. First, the formulation of the problem is discussed, and a condensed general equation is derived. Then, an end-to-end solution is proposed to find the responses of structures. The displacement response of each story has been carried out in both condensed and non-condensed general equations, and the results clearly show the accuracy of the proposed method. The numerical analysis and the results of the simulation of various friction-damped structures depicts the proposed approach consists with the commercial finite element method and is applicable for the analysis various types of structures. It is noted that the acceleration and displacement responses of the structures investigated under the proposed method and the traditional finite element method are so consistent that only a $1.5 \%$ difference is observed. Moreover, as a result of the proper allocation of degrees of freedom during the analysis, this method yields a reduction in computational costs especially in large buildings.
\end{abstract}

Keywords

analytical modeling, friction damper, matrix analysis, master-slave modeling, multi degree of freedom

\section{Introduction}

Structures in any geographic location may be subjected to natural hazards such as earthquakes. Although the inherent phenomena are inevitable, the impacts of earthquakes, and the cost of such disasters can be reduced if seismic control approaches are implemented within structures. In this way, analyzing soil and investigating total displacement formulations in the frequency domain has been suggested for structures with an embedded elastic foundation [1]. Another approach used semi-active base isolation control systems $[2,3]$.

However, the avoidance of structural collapse alone is not sufficient because the costs of finishes, contents, and sensitive instrumentation can be high. In this way if a major portion of the seismic energy independent of the primary structure is dissipated mechanically, then the destructive effects can be reduced [4]. With the emergence of passive energy dissipation systems such as friction dampers $[5,6]$, it became economically feasible to significantly increase resistance to earthquakes, and damage control potential of a structure. In general, frictional equipment performs well against earthquakes in such a way that their response is independent of the loading range and frequency, as well as the number of loading cycles. Two major types of frictional dampers are linear and rotational and operate on the principle of a coulomb damping [7]. Due to a rectangular hysteretic loop of a friction damper, as long as a building is sufficiently elastic, it tends to settle back to its original positions after an earthquake. One of the main aspects of this kind of damper is the higher energy dissipation due to the large area under the friction damper curve [8] which has led to a need for fewer devices for a certain level of earthquake.

The use of a friction damper results in a higher protection level for buildings against earthquakes [9-12]. Friction dampers are one of the most efficient methods of dissipating seismic energy. It has been shown that the efficiency of the energy dissipation of wall friction dampers under 
far-field earthquakes was $118 \%$ higher than that under near-field ones [13]. In another study [14], a rotational friction damper was investigated, and the modeling results showed $54 \%$ and $97 \%$ reductions in the maximum roof displacement and hysteresis energy, respectively. Recent researches [15] investigated five different damper location formats in SAP2000 based on the El Centro earthquake record. The results showed that the response of the structure i.e., the time period, story displacement, drift, and acceleration could be reduced by using a friction damper. However, it was shown that the percentage of the dissipation of the energy input through link hysteretic behavior depended upon the location and the number of friction dampers. Ontiveros-Pérez et al. [16] presented a methodology to reduce the maximum displacement at the top of a structure and the maximum inter-story drift using two objective functions. The results depicted a reduction of about 66 percent of the parameters. Mentioned in [17] and [18] discussed an improved friction damper, which is used in cross bracings with the difference that its central core was T-shaped. Four accelerograms of the Kobe, Naghan, Tabas and SanFernando earthquakes were used for a dynamic time-history analysis of the frames simulated in SAP2000. It was concluded that the improved friction damper could outperform in severe earthquakes such as Kobe and Tabas. The optimization of force as well as the position of the friction damper was addressed in [19]. The results proved that the proposed method was able to reduce the inter-story drift of a shear of a building by more than $65 \%$ and the maximum displacement at the top of the tower by approximately $55 \%$ with only three friction dampers. Since the above methods could not be used as practical cases because of the computational complexity, Nabid et al. [20] developed a more effective method in which they introduced an empirical design equation that maximized the energy dissipation of a wall friction damper. In a recent study Nabid et al. [21] presented a low computational method in which the computational costs were reduced up to 300 times compared to non-linear dynamic analyses.

All the above research assumed a spring-mass system in their processes. It must have assumed a very large degree of stiffness in their models, for springs in the non-sliding mode and zero stiffness in the sliding mode. As a result of this assumption, the stiffness of the element and deformation in the structural element would be different. This paper focuses on the most important aspects of friction damper modeling, i.e., a is frame analysis based on the behavior of each joint within the structure. In this way, an analytical matrix analysis method is proposed which is based on the master-slave modeling of joints. The main objective of this paper is to provide a more accurate practical approach for the dynamic analysis of friction -damped structures.

\section{Mathematical formulation}

\subsection{General equation in a MDOF system}

The analysis is started by modeling a friction joint as a multi-degree of freedom (MDOF) system. As can be seen in Fig. 1, in addition to two axial degrees of freedom (DOF) for friction $(i$ and $j$ ), it is also considered a vertical DOF (s) and a rotational DOF $(r)$. This is because the joints do not disconnect and work together. The following assumptions are considered: (a) the natural frequency of the friction -damped structure is constant; (b) the general equation is nonlinear due to the friction; (c) the end point is different from the starting point; (d) If the bracing force is less than the friction force, the slip behavior does not occur, and the system acts as a braced frame

The general equation in the MDOF's structure can be written as Eq. (1):

$\boldsymbol{M} \ddot{\boldsymbol{x}}(t)+\boldsymbol{C} \dot{\boldsymbol{x}}(t)+\boldsymbol{K} \boldsymbol{x}(t)=\boldsymbol{f}(t)$.

$\boldsymbol{M}$ is the mass matrix with a size of NDOF $\times \mathrm{NDOF} ; \boldsymbol{C}$ is the damping matrix with a size of NDOF $\times$ NDOF; $\boldsymbol{K}$ is the stiffness matrix with a size of NDOF $\times$ NDOF; NDOF is the number of DOFs; $\ddot{x}(t)$ is the acceleration response vector; $\dot{x}(t)$ is the velocity response vector; $x(t)$ is the displacement response vector; and $f(t)$ is the external force vector.

\subsection{General equation based on master-slave condensation}

Since actual industrial, structures are generally represented by very large finite element models, it is usually not possible to efficiently solve the set of non-linear Eq. (1)

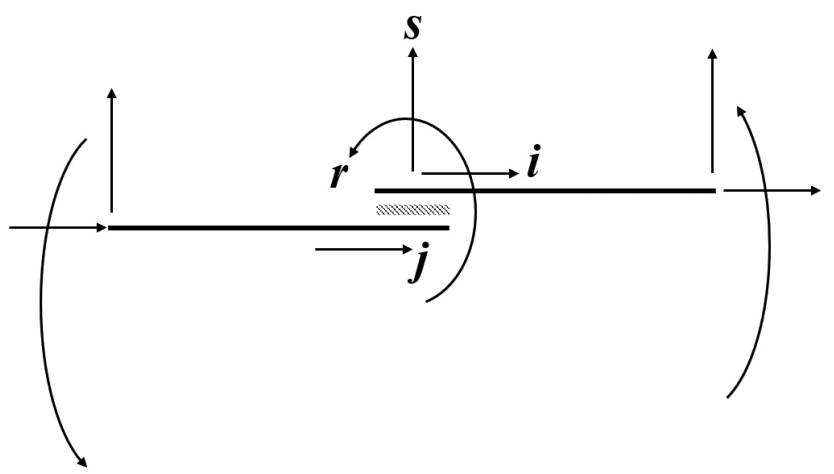

Fig. 1 Friction joints in a MDOF frame 
when $x(t)$ consists of the harmonic components of all the DOFs. Generally, it may be necessary to reduce a finite element model to a smaller size. In our previous research work [22], it was shown that condensation is a highly efficient method for a reducing model and saving computational costs. This paper therefore presents a practical low complexity algorithm, which is based on the reduced order DOF of a system. Therefore, using the mentioned theory, an accurate analysis of a structure's behavior is possible through the direct modeling of each joint of a structure. In this case, the general equation can be partitioned into master (index: $m$ ) and slave (index: $s$ ) ones to form Eq. (2).

$$
\left[\begin{array}{cc}
\boldsymbol{M}_{m m} & \boldsymbol{O}_{s m} \\
\boldsymbol{O}_{s m} & \boldsymbol{O}_{s s}
\end{array}\right]\left[\begin{array}{c}
\ddot{\boldsymbol{x}}_{m} \\
\ddot{\boldsymbol{x}}_{s}
\end{array}\right]+\left[\begin{array}{cc}
\boldsymbol{K}_{m m} & \boldsymbol{K}_{m s} \\
\boldsymbol{K}_{s m} & \boldsymbol{K}_{s s}
\end{array}\right]\left[\begin{array}{c}
\boldsymbol{x}_{m} \\
\boldsymbol{x}_{s}
\end{array}\right]=\left[\begin{array}{c}
\boldsymbol{f}_{m} \\
\boldsymbol{f}_{s}
\end{array}\right]
$$

$\boldsymbol{x}_{m}$ is the displacement vector of the master DOFs; $\boldsymbol{x}_{s}$ is the displacement vector of the slave DOFs; $\boldsymbol{K}_{m m} \cdot \boldsymbol{K}_{m s} \cdot \boldsymbol{K}_{s m}$ and $\boldsymbol{K}_{s s}$ are partitions of the stiffness matrix; $\boldsymbol{M}_{m m}$ is the main partition of the mass matrix; $\boldsymbol{O}_{m s} . \boldsymbol{O}_{s m}$ and $\boldsymbol{O}_{s s}$ are null partitions of the mass matrix; $\boldsymbol{f}_{m}$ is the external force vector on the master DOFs; and $\boldsymbol{f}_{s}$ is the external force vector on the slave DOFs. By expanding of Eq. (2), the Eq. (3) and (4) are formed:

$$
\begin{aligned}
& \boldsymbol{M}_{m m} \ddot{\boldsymbol{x}}_{m}+\boldsymbol{K}_{m m} \boldsymbol{x}_{m}+\boldsymbol{K}_{m s} \boldsymbol{x}_{s}=\boldsymbol{f}_{m}, \\
& \boldsymbol{K}_{s m} \boldsymbol{x}_{m}+\boldsymbol{K}_{s s} \boldsymbol{x}_{s}=\boldsymbol{f}_{s} \cdot \boldsymbol{x}_{s}=\boldsymbol{K}_{s s}{ }^{-1}\left(\boldsymbol{f}_{s}-\boldsymbol{K}_{s m} \boldsymbol{x}_{m}\right) .
\end{aligned}
$$

By applying the results of Eq. (4) into Eq. (3), Eq. (5) is obtained:

$$
\boldsymbol{M}_{m m} \ddot{\boldsymbol{x}}_{m}+\left(\boldsymbol{K}_{m m}-\boldsymbol{K}_{m s} \boldsymbol{K}_{s s}{ }^{-1} \boldsymbol{K}_{s m}\right) \boldsymbol{x}_{m}=\boldsymbol{f}_{m}-\boldsymbol{K}_{m s} \boldsymbol{K}_{s s}^{-1} \boldsymbol{f}_{s} .
$$

So, in comparing Eq. (5) with the traditional general equation the condensed or reduced mass and stiffness matrices, can be extracted as Eqs. (6-7):

$$
\begin{aligned}
& \boldsymbol{M}^{*}=\boldsymbol{M}_{m m}, \\
& \boldsymbol{K}^{*}=\boldsymbol{K}_{m m}-\boldsymbol{K}_{m s} \boldsymbol{K}_{s s}{ }^{-1} \boldsymbol{K}_{s m} .
\end{aligned}
$$

The reduced external force vector is defined as Eq. (8):

$$
\boldsymbol{f}^{*}=\boldsymbol{f}_{m}-\boldsymbol{K}_{m s} \boldsymbol{K}_{s s}^{-1} \boldsymbol{f}_{s} \text {. }
$$

The general equation of a system can then be redefined based on the master DOFs as Eq. (9):

$$
\boldsymbol{M}^{*} \ddot{\boldsymbol{x}}_{m}+\boldsymbol{K}^{*} \boldsymbol{x}_{m}=f^{*}
$$

In the condensed general equation, the external force vector of the master DOFs, $f_{m}$, is actually the seismic force (i.e., the earthquake). In the same way, the vector of the forces related to the slave DOFs, $f_{s}$, is the vector in which the frictional forces are placed. To achieve the velocity of the slave DOFs, $\dot{x}_{s}$, by considering Eq. (4), it can obtain the differentiation of this vector as Eq. (10):

$$
\begin{aligned}
& \boldsymbol{x}_{s}=\boldsymbol{K}_{s s}{ }^{-1} \boldsymbol{f}_{s}-\boldsymbol{K}_{s s}{ }^{-1} \boldsymbol{K}_{s m} \boldsymbol{x}_{m} \frac{d}{d t} \boldsymbol{x}_{s} \\
& =\boldsymbol{K}_{s s}{ }^{-1} \frac{d}{d t} \boldsymbol{f}_{s}-\boldsymbol{K}_{s s}{ }^{-1} \boldsymbol{K}_{s m} \frac{d}{d t} \boldsymbol{x}_{m} .
\end{aligned}
$$

Hence, it is considered that the vector of the frictional forces of slave DOFs is equal to the zero vector $\left(\frac{d}{d t} f_{s} \cong\{0\}\right)$. Therefore, the velocity vector of the slave DOFs is approximately redefined as Eq. (11):

$\dot{\boldsymbol{x}}_{s} \cong-\boldsymbol{K}_{s s}{ }^{-1} \boldsymbol{K}_{s m} \dot{\boldsymbol{x}}_{m}$.

Eq. (11) lets us define the velocity of the slave DOFs in the terms of the master DOFs. In fact, through this important relation the condensed general equation can be solved in a lower degree. To obtain the actual general equation of a structure that explains the behavior of each member, it needs to determine the system stiffness matrix as defined in Eq. (12):

$$
\begin{aligned}
& \boldsymbol{K}=\sum_{i=1}^{N E L} \boldsymbol{T}_{i}^{T} \boldsymbol{R}_{i}^{T} \boldsymbol{k}_{i} \boldsymbol{R}_{i} \boldsymbol{T}_{i} . \\
& \boldsymbol{K}_{m m}, \boldsymbol{K}_{m s}, \boldsymbol{K}_{s s}, \boldsymbol{K}_{s m} \text { and } \boldsymbol{K}_{s s} \text { are defined as follows: }
\end{aligned}
$$

$$
\begin{aligned}
& \boldsymbol{K}_{m m}=\operatorname{submatrix}\left(\boldsymbol{K}, 1, n_{\text {story }}, 1, n_{\text {story }}\right), \\
& \boldsymbol{K}_{m s}=\operatorname{submatrix}\left(\boldsymbol{K}, 1, n_{\text {story }}, n_{\text {story }}+1, D O F\right), \\
& \boldsymbol{K}_{\text {sm }}=\operatorname{submatrix}\left(\boldsymbol{K}, n_{\text {story }}+1, D O F, 1, n_{\text {story }}\right), \\
& \boldsymbol{K}_{s s}=\operatorname{submatrix}\left(\boldsymbol{K}, n_{\text {story }}+1, D O F, n_{\text {story }}+1, D O F\right) .
\end{aligned}
$$

In Eq. (12), $T_{i}$ is the member's transformation matrix, which correlates the member's local degrees of freedom to the system's global degrees of freedom; $R_{i}$ is the member's rotation matrix, which rotates the direction of the local degrees of freedom to the global directions; and $k_{i}$ is the member's stiffness matrix in a rank of $6 \times 6$ [23].

\subsection{Matrix analysis of the condensed general equation}

Based on the proposed condensation method discussed in Section 2.2, now it is going to present the end-to-end solution to find the response of the condensed general equation in Eq. (9), which gives the dynamic responses of a system equipped with friction dampers. The main concern of our model is that four independent degrees for each frictional 
damper is considered. In this way, each node can be stabilized by defining two axials (i.e., a vertical and a rotational degree of freedom). Moreover, the total number of DOFs of the structure is divided into master and slave ones, and the general equation is only solved for the master DOFs. Fig. 2 illustrates the conceptual diagram of the proposed approach. To analyze a structure, first it is needed to set the initial set of parameters such as the number of stories, section area of an element, node coordination matrix, the element coordination matrix, and finally the earthquake records as an external force. After the mentioned parameters are entered, the data process will be now started. In this step the necessary data would be extracted in order to form the condensed general equation. Then, the stiffness matrix and its partitions are calculated based on Eqs. (12-13), respectively. Now the general equation of the system can be formed using Eq. (9). To solve a general equation, the Newmark- $\beta$ method is used. Although the method is discussed in many textbooks in structural dynamics [24], a brief description of this method as specialized for a nonlinear force deformation model is provided here. The Newmark- $\beta$ method is based on the solution of an incremental form of general equation. Two approaches are presented, i.e., displacement-based and acceleration based. Since using a damper causes the structural response to be maintained in a linear area, the Newmark's method is used which assumes a linear acceleration over a small time interval, $\Delta t$.

Assuming a certain specific variation for the acceleration within the time interval the incremental displacement, velocity, and acceleration can be written as

$$
\begin{aligned}
& \boldsymbol{M}^{*} \ddot{\boldsymbol{x}}_{i}+\boldsymbol{C} \dot{\boldsymbol{x}}_{i}+\boldsymbol{K}^{*} \boldsymbol{x}_{i}=\boldsymbol{f}_{i}, \\
& \boldsymbol{M}^{*} \ddot{\boldsymbol{x}}_{i+1}+\boldsymbol{C} \dot{\boldsymbol{x}}_{i+1}+\boldsymbol{K}^{*} \boldsymbol{x}_{i+1}=\boldsymbol{f}_{i+1}, \\
& \dot{\boldsymbol{x}}_{i+1}=\dot{\boldsymbol{x}}_{i}+[(1-\gamma) \Delta t] \ddot{\boldsymbol{x}}_{i}+(\gamma \Delta t) \ddot{\boldsymbol{x}}_{i+1}, \\
& \boldsymbol{x}_{i+1}=\boldsymbol{x}_{i}+\Delta t \dot{\boldsymbol{x}}_{i}+\left[\left(\frac{1}{2}-\beta\right) \Delta t^{2} \ddot{\boldsymbol{x}}_{i}\right]+\left(\beta \Delta t^{2}\right) \ddot{\boldsymbol{x}}_{i+1}
\end{aligned}
$$

$x_{i}$ : displacement at moment $i ; \dot{x}_{i+1}$ : displacement at moment $i+1 ; \dot{x}_{i}$ : velocity at moment $i ; \dot{x}_{i+1}$ : velocity at moment $i+1 ; \dot{x}_{i+1}$ : acceleration at moment $i ; \dot{x}_{i+1}$ : acceleration at moment $i+1$.

$\boldsymbol{M}^{*}$ : reduced mass matrix, $\boldsymbol{K}^{*}:$ reduced stiffness matrix, $\boldsymbol{C}$ : damping matrix, and $\beta$ is Newmark's constant, $\gamma=1 / 2$, $\beta=1 / 6$ for the linear acceleration method.

In order to preserve the Newmark- $\beta$ method's stability, the critical time step, $N_{0}$, is defined as Eq. (15):

$$
N_{0}=t . \Delta t, \frac{\Delta t}{T_{f}} \leq \frac{1}{\pi \sqrt{2}} \frac{1}{\sqrt{\gamma-2 \beta}} .
$$

$T_{f}$ is the largest natural period of the structure.

In order to verify the accuracy of the condensed general equation, the Runge-Kutta numerical method is used [25]. In fact, it is going to show the structural response in both non-condensed and condensed general equations. The former is solved by Newmark- $\beta$ method, and the latter is solved by the Runge-Kutta method. The most commonly used constants in using a fourth order Runge-Kutta method give the following series of formulas:

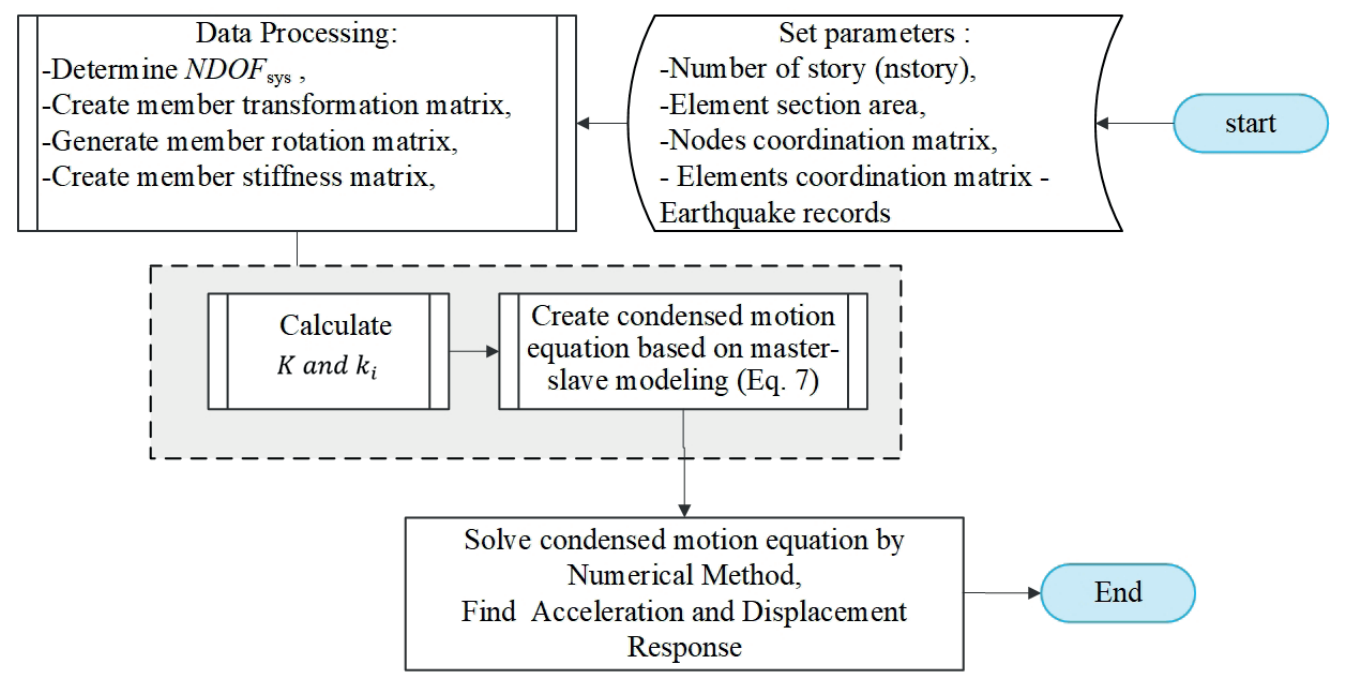

Fig. 2 Conceptual diagram of the proposed matrix analysis method 
$\ddot{\boldsymbol{x}}_{i+1}=\ddot{\boldsymbol{x}}_{i}+\frac{1}{6}\left(\boldsymbol{k}_{1}+2 \boldsymbol{k}_{2}+2 \boldsymbol{k}_{3}+\boldsymbol{k}_{4}\right)$,

$\boldsymbol{k}_{1}=h \cdot f\left(\boldsymbol{x}_{i}, \ddot{\boldsymbol{x}}_{i}\right)$,

$\boldsymbol{k}_{2}=h \cdot f\left(\boldsymbol{x}_{i}+\frac{1}{6} \cdot h, \ddot{\boldsymbol{x}}_{i}+\frac{1}{2} \boldsymbol{k}_{1}\right)$,

$\boldsymbol{k}_{3}=h \cdot f\left(\boldsymbol{x}_{i}+\frac{1}{2} \cdot h, \ddot{\boldsymbol{x}}_{i}+\frac{1}{2} \boldsymbol{k}_{2}\right)$,

$\boldsymbol{k}_{4}=h \cdot f\left(\boldsymbol{x}_{i}+h, \ddot{\boldsymbol{x}}_{i}+\boldsymbol{k}_{3}\right)$.

\section{Results and discussion}

\subsection{Four-story building with a friction damper}

To assess the performance of the proposed method, first the behavior of the system is investigated in detail. Fig. 3 shows the analyzed frame under the proposed method. Based on our method, the total DOFs of the system is divided into 4 master DOFs and 32 slave DOFs. A general equation is formed that is based on the master DOFs. Then, the procedure for the matrix analysis method as explained in Fig. 2 is used to find the displacement response of some DOFs by the proposed method, including a condensed general equation based on the master-slave theory. In order to compare the results, the response of each story is first investigated with both methods, i.e., the traditional non-condensed general equation and the proposed condensed general equation.

The simulation results of both methods are illustrated in Fig. 4. The external force is an impulse function with a duration of $8 \mathrm{~s}$ and $\Delta t=0.005 \mathrm{~s}$. The Runge-Kutta method

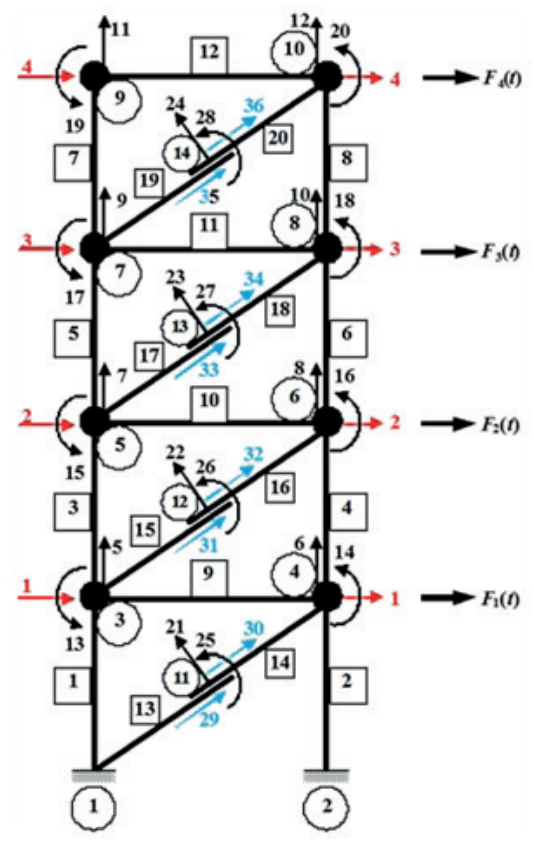

Fig. 3 Analyzed four-story friction-damped structure frame under the proposed matrix analysis method

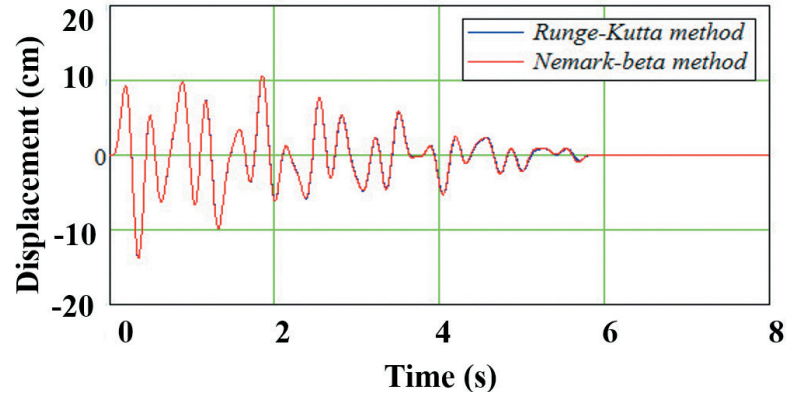

(a)

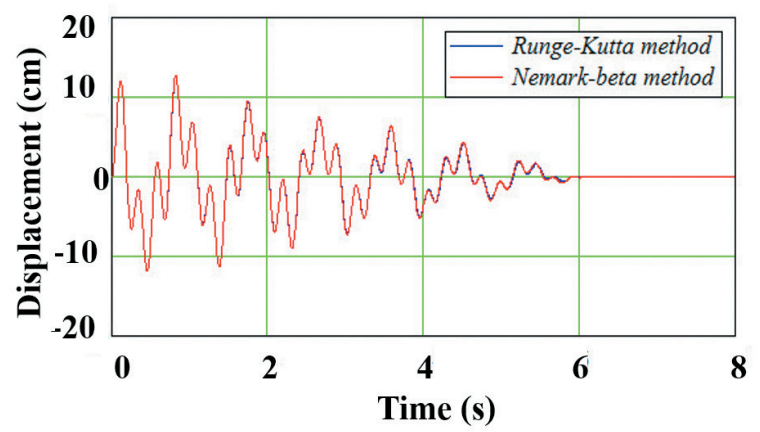

(b)

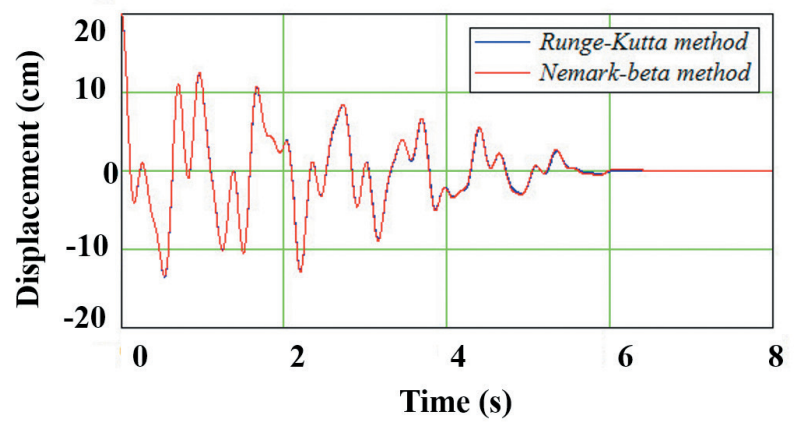

(c)

Fig. 4 Comparison of the condensed general equation by the Newmark method and the non-condensed one by the Runge-Kutta method under an impulse function (a) displacement at Story\# 1; (b) displacement at Story\# 2; (c) displacement at Story\# 3

is used to solve the non-condensed general equation, and the Newmark method is used for the proposed condensed general equation. The simulations are carried out in Mathcad software. Fig. 4 demonstrated that the response of both methods is close to each other. This is despite the fact that in the proposed method, the computational cost and time of the situation would be reduced.

This is because the actions from the presented method are based on a reduced number of degrees of freedom, instead of the total number of equilibrium equations and non-zero stiffness terms. So, the order of complexity is limited by the number of operations for the formation of the local matrices of one element. Also, in the Newmark method second-order ODEs can be solved directly without 
having to convert them into a state-space which is necessary for Runge-Kutta methods. This means fewer DOFs; hence a lower computational cost, when compared to the Runge-Kutta methods.

The structure is then analyzed with relation to Tabas and Chi-Chi earthquakes. Fig. 5 shows the records for the above mentioned earthquakes.

The displacement and acceleration responses of the four -story frame analyzed under the proposed algorithm and the Tabas earthquake are illustrated in Fig. 6. In a similar way, Fig. 7 shows the response of the four -story building under the Chi-chi earthquake.

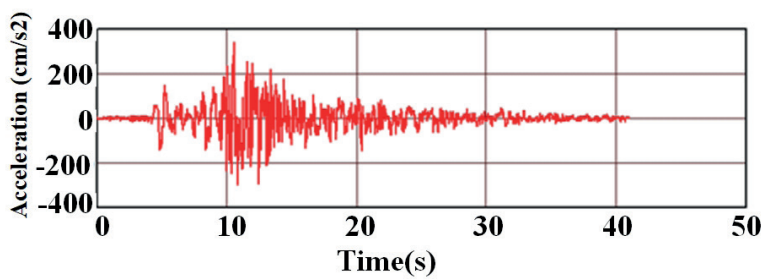

(a)

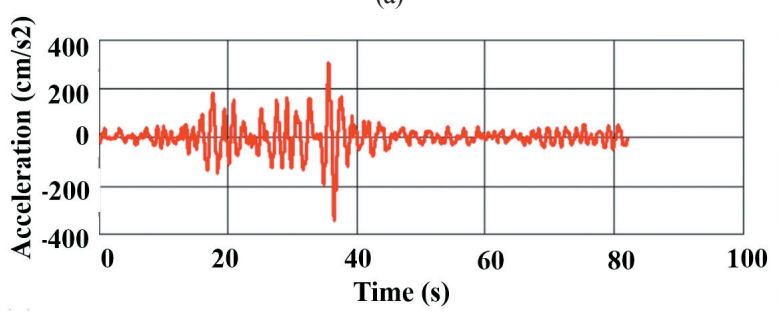

(b)

Fig. 5 Earthquake records of (a) Tabas; (b) Chi-Chi

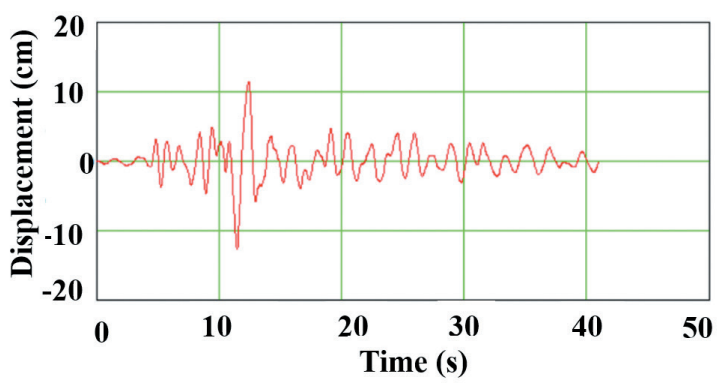

(a)

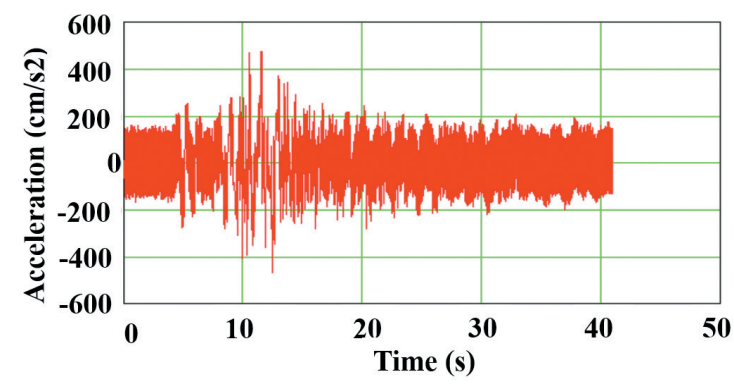

(b)

Fig. 6 Response of the four-story friction-damped structure using the proposed method, under Tabas earthquake (a) Displacement; (b) Acceleration
In order to verify the method presented, the frame of Fig. 3 is analyzed by other FEM software such as OpenSees. The results of the comparison are shown on Fig. 8. Also, the first 4 natural frequencies according to both methods were determined to be $6.258,17.766,30.173$, and 47.424 .

\subsection{Six and ten- story building with a friction damper}

For the second scenario, two-bay six story and a tenstory friction-damped building are investigated in which one friction damper is used on each floor. The analyzed structures under the proposed method are shown in Fig. 9. The degrees of freedom for a corner joint and an internal friction joint are three and four respectively. The acceleration and displacement responses of six and ten storys are shown in Figs. 10 and 11, respectively.

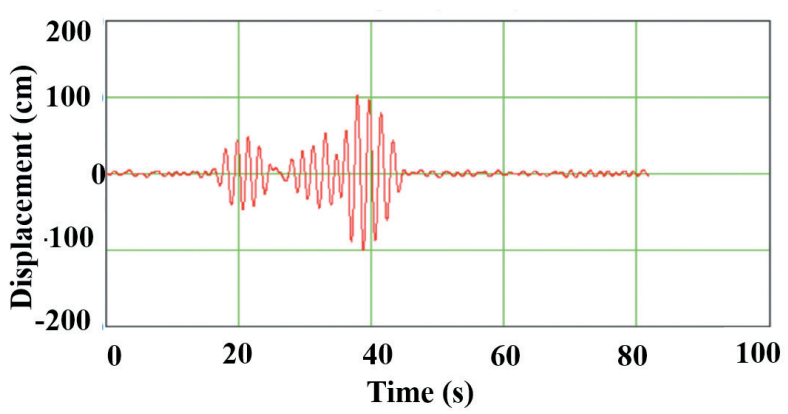

(a)

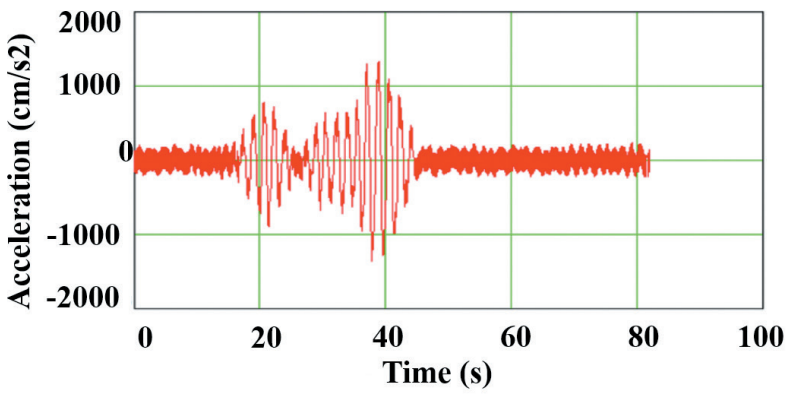

(b)

Fig. 7 Response of the four- story friction- damped structure using the proposed method, under the Chi-Chi earthquake (a) Displacement; (b) Acceleration

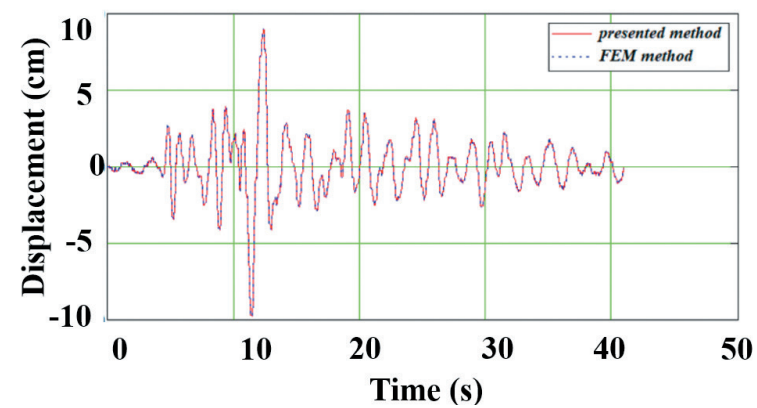

Fig. 8 Comparison of the four-story-friction damped structure's displacement according to different methods under the Tabas earthquake 


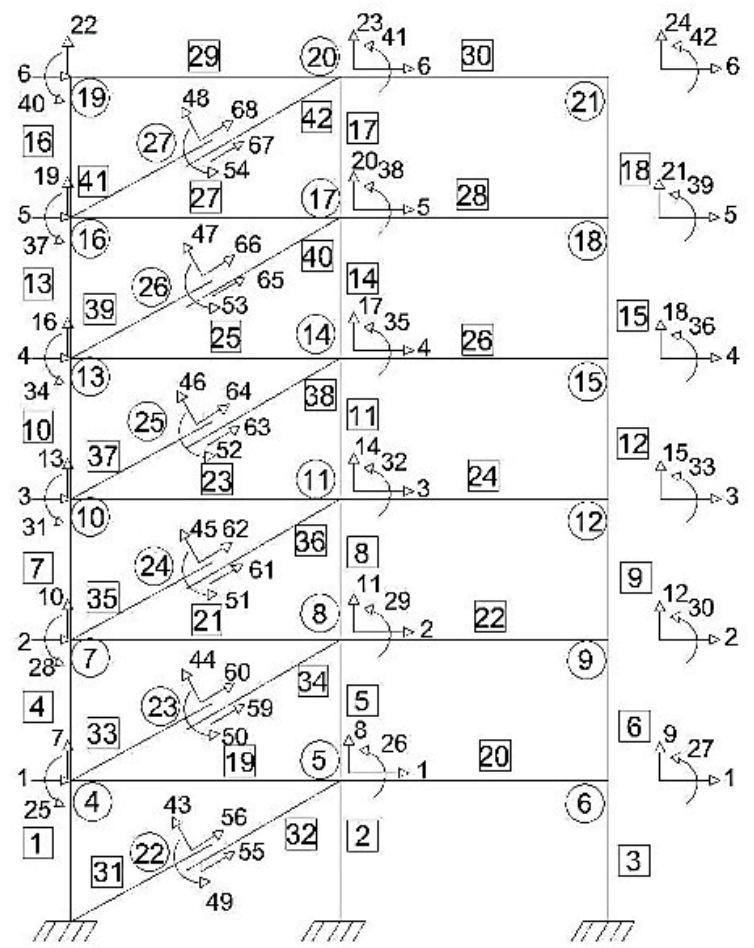

(1)
(2)

(a)

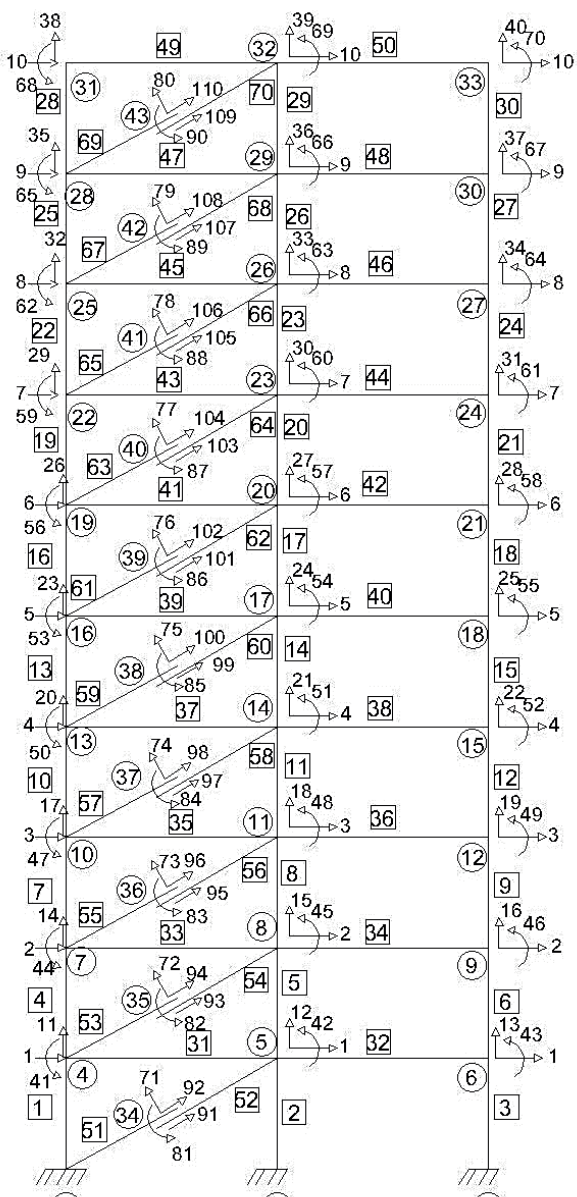

(1)

(2)

(b)

Fig. 9 Frame Specification of (a) two-bay six story friction-damped structure; (b) two-bay ten story friction-damped structure

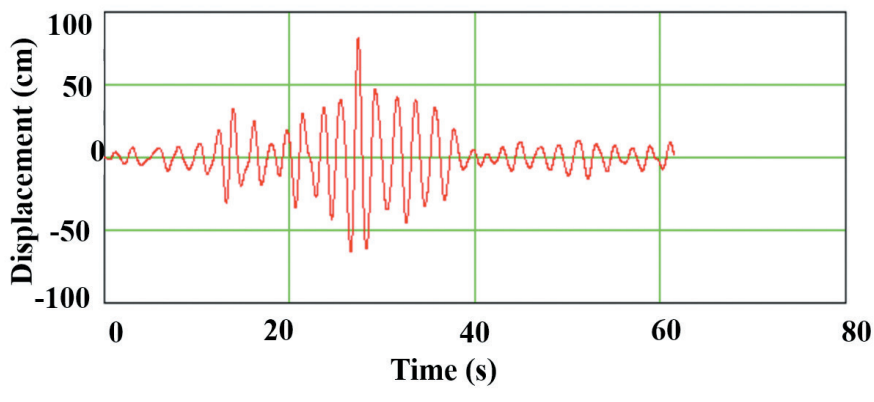

(a)

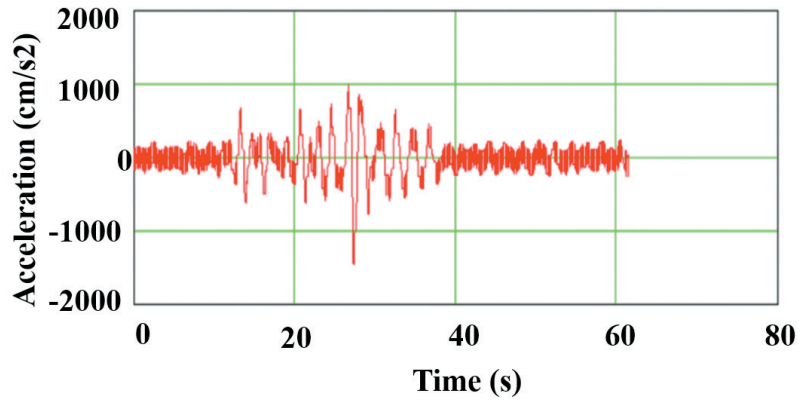

(b)

Fig. 10 Time responses of a six-story under the Chichi earthquake (a) displacement of two-bay six-story; (b) acceleration of two-bay six-story

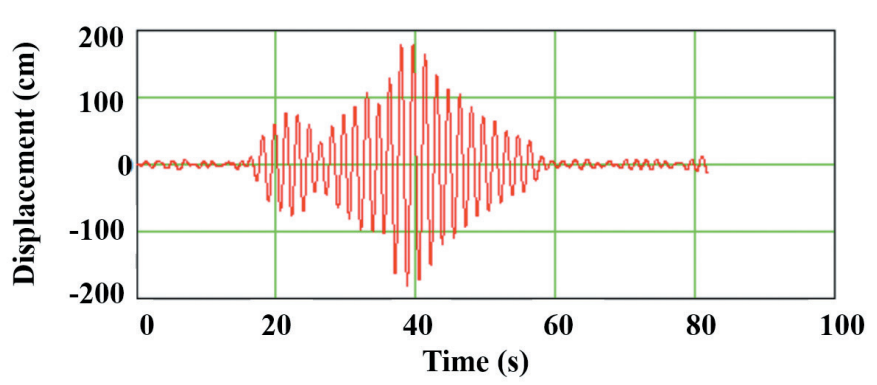

(a)

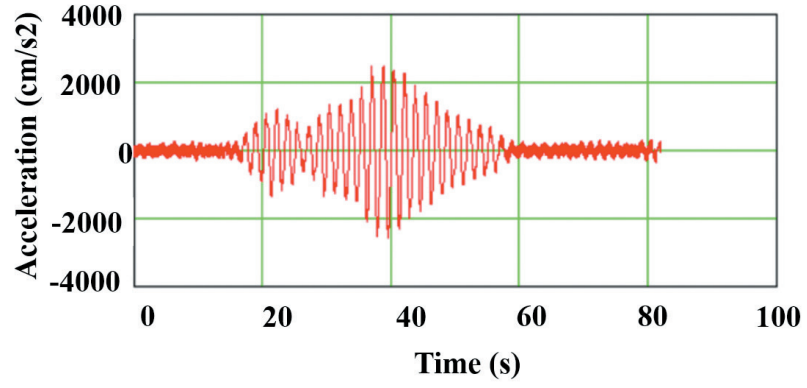

(b)

Fig. 11 Time responses of a ten-story under the Chichi earthquake (a) displacement of two-bay ten-story; (b) acceleration of two-bay ten-story 
Table 1 Maximum acceleration and displacement of four- story bend ing frame structure under different earthquakes

\begin{tabular}{|c|c|c|c|c|c|c|c|}
\hline \multirow{2}{*}{ Earthquake } & \multirow{2}{*}{ Parameter } & \multicolumn{2}{|c|}{ Traditional FEM Software } & \multicolumn{2}{|c|}{ Proposed Method } & \multicolumn{2}{|c|}{ Deviation (\%) } \\
\hline & & 1-Bay & 2-Bay & 1-Bay & 2-Bay & 1-Bay & 2-Bay \\
\hline \multirow{2}{*}{$\begin{array}{l}\text { Manjil, (1990), } \\
\text { PGA (cm/s/s): } 28.21\end{array}$} & Acceleration $\left(\mathrm{m} / \mathrm{s}^{2}\right)$ & 10.90 & 12.68 & 11.06 & 12.79 & 1.4 & 0.86 \\
\hline & Displacement (cm) & 29.202 & 31.89 & 29.66 & 32.01 & 1.5 & 0.37 \\
\hline \multirow{2}{*}{$\begin{array}{l}\text { Kobe, }(1995), \\
\text { PGA }(\mathrm{cm} / \mathrm{s} / \mathrm{s}): 603.61\end{array}$} & Acceleration $\left(\mathrm{m} / \mathrm{s}^{2}\right)$ & 7.82 & 10.89 & 7.89 & 10.92 & 0.8 & 0.27 \\
\hline & Displacement $(\mathrm{cm})$ & 17.86 & 19.76 & 18.03 & 19.8 & 0.94 & 0.20 \\
\hline \multirow{2}{*}{$\begin{array}{l}\text { El-Centro, (1940), PGA } \\
(\mathrm{cm} / \mathrm{s} / \mathrm{s}): 210.14\end{array}$} & Acceleration $\left(\mathrm{m} / \mathrm{s}^{2}\right)$ & 14.38 & 10.63 & 14.49 & 10.79 & 0.75 & 1.48 \\
\hline & Displacement $(\mathrm{cm})$ & 29.87 & 23.96 & 30.02 & 24.1 & 0.5 & 0.58 \\
\hline
\end{tabular}

Table 1 depicts the results of the comparison of the 1-bay and 2-bay four -story buildings under different earthquakes. For a further investigation 6-, 7-, 10-, and 14-story are analyzed, both 1-bay and 2-bay, equipped structures with friction dampers (see Fig. 12). As it is expected, the proposed method can be exploited for any structure with different numbers of stories. The results show that analyzing the structures using the proposed method are in a good agreement with traditional software.

The performance of the proposed algorithm can be proved, and it can be effective for estimating the acceleration parameters of various structures. The small differences between the two methods occur due to the output sampling time interval used for them.

The running time of the proposed algorithm and traditional FEM software are compared in Fig. 13. Running time is a time that the software needs to analyze the structures. The proposed algorithm is carried out in Mathcad software and the hardware specification in both tests is Corei7@1.8GHz processor. The result depicts that the running time of the proposed method is lower than that of traditional FEM software especially in the case of high stories.

For proving the results of this paper, similar works are reviewed in which the various friction damped structures have been analyzed. Most of them focused on displacement.

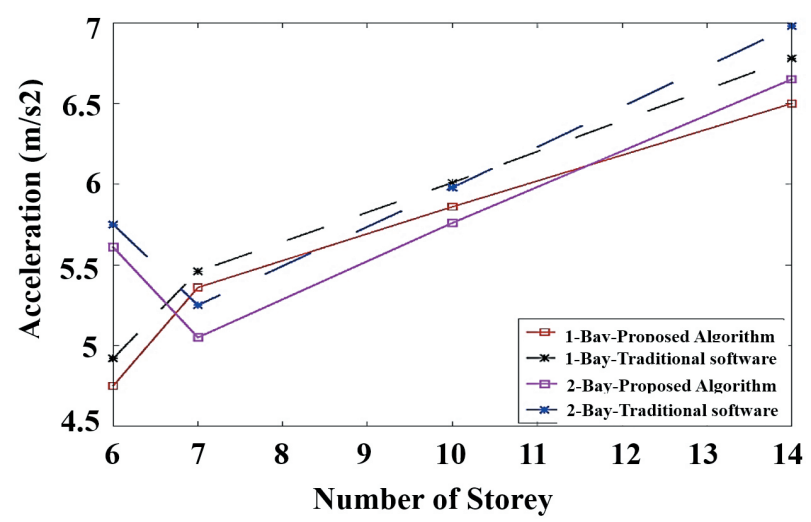

Fig. 12 Comparison of the peak acceleration of various structures with the proposed and traditional methods
Also, some of them as noted in the Table 2, are reported both displacement and acceleration in their research. They are concluded and the analogy of this paper and the other references are summarized in Table 2. Moreover, the statistical results are depicted in Fig. 14 to clarify the consistency of this paper with the other references.

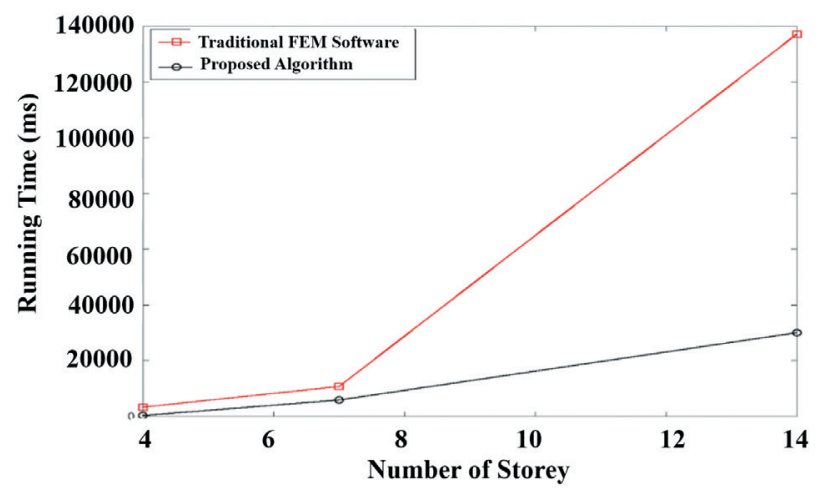

Fig. 13 Comparison of running time with proposed and traditional methods

Table 2 Verification of results of this paper with similar research

\begin{tabular}{|c|c|c|c|}
\hline Reference & $\begin{array}{l}\text { Structure } \\
\text { Under Test }\end{array}$ & $\begin{array}{c}\text { Displacement/ } \\
\text { Inter-story Drift (m) }\end{array}$ & $\begin{array}{l}\text { Acceleration } \\
\left(\mathrm{m} / \mathrm{s}^{2}\right)\end{array}$ \\
\hline $\begin{array}{l}{[26]} \\
\text { This paper }\end{array}$ & 6-story & $\begin{array}{l}0.004409 \\
0.004403\end{array}$ & - \\
\hline $\begin{array}{l}{[27]} \\
\text { This paper }\end{array}$ & 4-Story & $\begin{array}{l}0.027 \\
0.030\end{array}$ & $\begin{array}{l}5.01 \\
5.08\end{array}$ \\
\hline $\begin{array}{l}{[28]} \\
\text { This paper }\end{array}$ & 4-story & $\begin{array}{l}0.036 \\
0.038\end{array}$ & $\begin{array}{l}4.72 \\
4.75\end{array}$ \\
\hline $\begin{array}{l}{[29]} \\
\text { This paper }\end{array}$ & 4-story & $\begin{array}{l}0.005595 \\
0.005598\end{array}$ & - \\
\hline $\begin{array}{l}{[30]} \\
\text { This paper }\end{array}$ & 6-story & $\begin{array}{l}0.047 \\
0.049\end{array}$ & - \\
\hline $\begin{array}{l}{[31]} \\
\text { This paper }\end{array}$ & 4-story & $\begin{array}{c}0.008 \\
0.0083\end{array}$ & \\
\hline $\begin{array}{l}{[19]} \\
\text { This paper }\end{array}$ & 6-story & $\begin{array}{l}0.004409 \\
0.004412\end{array}$ & - \\
\hline $\begin{array}{l}{[32]} \\
\text { This paper }\end{array}$ & 9-story & 0.01850 .0187 & $\begin{array}{l}4.28 \\
4.30\end{array}$ \\
\hline
\end{tabular}




\section{Displacement}

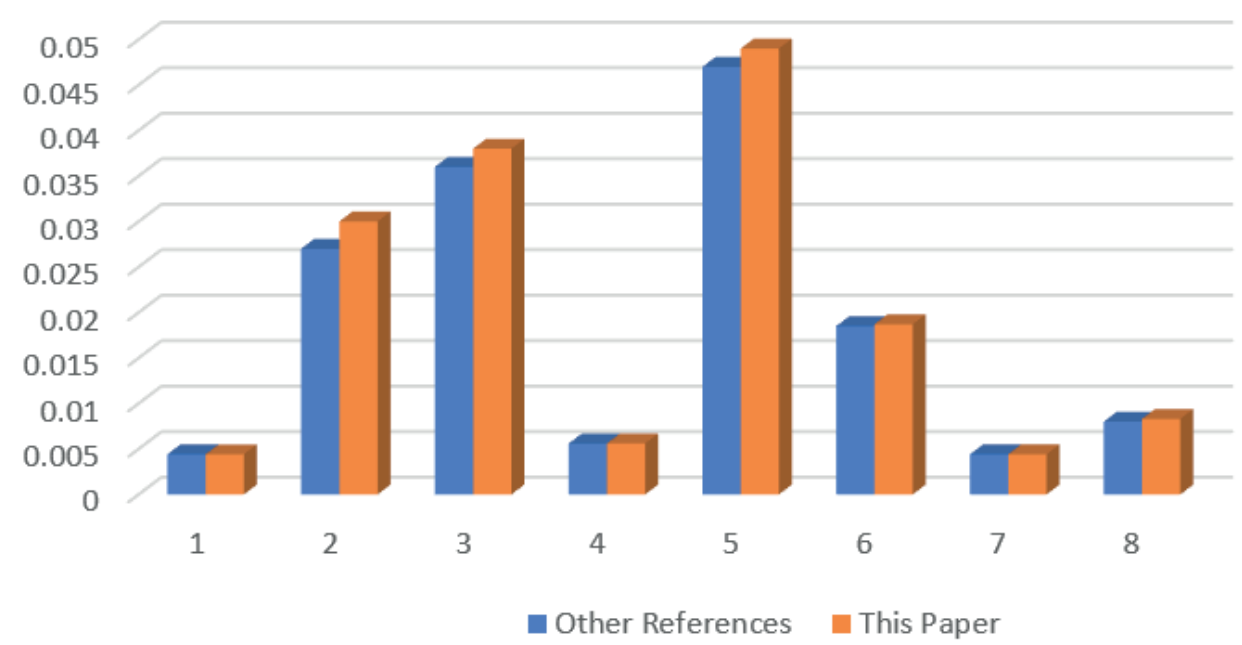

(a)

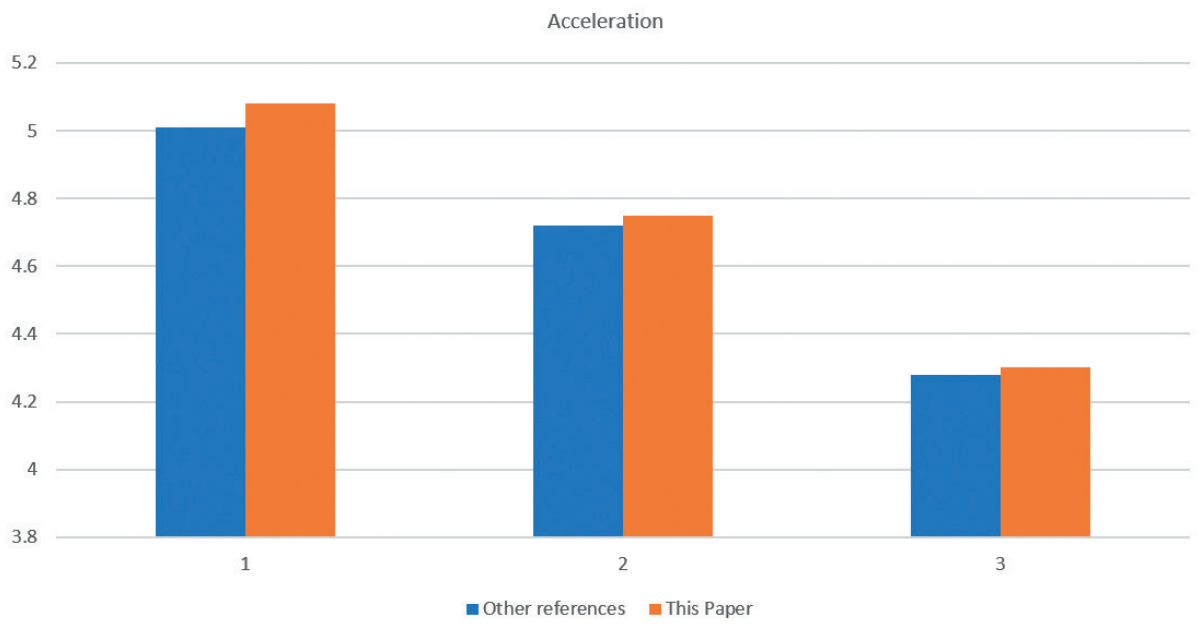

(b)

Fig. 14 Comparison results of this paper with other references of Table 2

\section{Conclusions}

This work presented the matrix analysis method in order to analyze the behavior of friction- damped structures. In the proposed method, the total DOFs are divided into master and slaves, and the frictional joints are modeled by 4 DOFs. In this way, the condensed general equation is extracted in which only dynamic loading was occurred on the master DOFs, and the slaves act as a static DOFs and could be presented based on the responses of the master DOFs. Then, end -to -end solution was designed based on the matrix analysis and numerical methods. Both the proposed method and the traditional non-condensed methods were investigated, and the results of the solution by the Runge-Kutta and Newmark methods were compared.
Also, the proposed method was implemented for 4-, 6-, 10-, and 14-story 1-bay and 2-bay structures under different earthquake records. A comparison of the results of the proposed method and traditional FEM software showed minimum and maximum deviations of $0.2 \%$ and $1.5 \%$, respectively. Moreover, in order to verify the performance of the proposed analytical method some similar works are investigated that are addressed in Table 2. The two parameters of displacement and acceleration are considered. The comparison results illustrated that the proposed method has a good consistency with the other investigations. Another notable aspect of the presented method was its lower running time in such a way that by increasing the number of stories, it was about $20 \%$ lower 
than that of the traditional methods. For further study, we are going to extend the proposed analysis method for tall buildings. Another idea is to implement the proposed method to analyze the structures equipped with diagonal friction damper.

\section{References}

[1] Králik, J. "Deterministic and probabilistic analysis of damping device resistance under impact loads from nuclear fuel container drop", Slovak Journal of Civil Engineering, 18(1), pp. 1-16, 2010. https://doi.org/10.2478/v10189-010-0004-6

[2] Dadkhah, H., Noruzvand, M. "Optimal Response-Related Weighting Matrices to Control Semi-Active Base Isolation Systems", Slovak Journal of Civil Engineering, 25(2), pp. 24-32, 2017. https://doi.org/10.1515/sjce-2017-0009

[3] Ounis, H. M., Ounis, A. "Parameters influencing the response of a base-isolated building", Slovak Journal of Civil Engineering, 21(3), pp. 31-42, 2013.

https://doi.org/10.2478/sjce-2013-0014

[4] Armali, M., Damerji, H., Hallal, J., Fakih, M. "Effectiveness of friction dampers on the seismic behavior of high rise building VS shear wall system", Engineering Reports, 1(5), Article ID: e12075, 2019. https://doi.org/10.1002/eng2.12075

[5] Pall, A. S., Pall, R. "Friction-dampers for seismic control of buildings, A Canadian experience", presented at the Eleventh World Conference on Earthquake Engineering, Acapulco, Mexico, June, 23-28, 1996, Paper No. 497.

[6] Soong, T. T., Dargush, G. F. "Passive Energy Dissipation Systems in Structural Engineering", John Wiley \& Sons, London, UK, 1997. https://doi.org/10.1002/stc.4300060114

[7] Shaw, S. W. "On the dynamic response of a system with dry friction", Journal of Sound and Vibration, 108(2), pp. 305-325, 1986. https://doi.org/10.1016/S0022-460X(86)80058-X

[8] Pall, A., Pall, R. T. "Performance-based design using pall friction dampers-an economical design solution", [pdf] presented at the 13th World Conference on Earthquake Engineering, Vancouver, BC, Canada, Aug. 1-6, 2004, Paper No. 1955. Available at: https://www. iitk.ac.in/nicee/wcee/article/13_1955.pdf

[9] Quintana, H. C., Petkovski, M. "Optimum performance of structural control with friction dampers", Engineering Structures, 172, pp. 154-162, 2018.

https://doi.org/10.1016/j.engstruct.2018.06.017

[10] Sheikhi, J., Fathi, M., Rahnavard, R., Napolitano, R. "Numerical analysis of natural rubber bearing equipped with steel and shape memory alloys dampers", Structures, 32, pp. 1839-1855, 2021. https://doi.org/10.1016/j.istruc.2021.03.115

[11] Rahnavard, R., Rebelo, C., Craverio, H. D., Napolitano, R. "Numerical investigation of the cyclic performance of reinforced concrete frames equipped with a combination of a rubber core and a U-shaped metallic damper", Engineering Structures, 225, Article number: 111307, 2020

https://doi.org/10.1016/j.engstruct.2020.111307

\section{Acknowledgement}

Special thanks to Dr. Mohammad Sadegh Rohanimanesh, faculty of the Islamic Azad University-Central Tehran branch and Dr. Mahmood Hosseini, faculty of the Eastern Mediterranean University, for own reviewing and comments that greatly improved this research.

[12] Sheikhi, J., Fathi, M., Rahnavard, R. "Natural rubber bearing incorporated with high toughness steel ring dampers", Structures, 24, pp. 107-123, 2020. https://doi.org/10.1016/j.istruc.2020.01.013

[13] Nabid, N. Hajirasouli, I., Petkovski, M. "Adaptive low computational cost optimization method for performance-based seismic design of friction dampers", Engineering Structures, 198, Article number: 109549, 2019. https://doi.org/10.1016/j.engstruct.2019.109549

[14] Jarrahi, H., Asadi, A., Khatibinia, M., Etedali, S. "Optimal design of rotational friction dampers for improving seismic performance of inelastic structures", Journal of Building Engineering, 27, Article number: 100960,2020

https://doi.org/10.1016/j.jobe.2019.100960

[15] Sanghai, S. S., Pawade, P. Y. "Effect of the Position and Number of Friction Dampers on the Seismic Response of Frame", International Journal of Earth Science and Engineering, 7(5), pp. 1854-1859, 2014.

[16] Ontiveros-Pérez, S. P., Fleck Fadel Miguel, L., Fadel Miguel, L. "A New Assessment in the Simultaneous Optimization of Friction Dampers in Plane and Spatial Civil Structures", Mathematical Problems in Engineering, 2017, Article ID 6040986, 2017. https://doi.org/10.1155/2017/6040986

[17] Wu, B., Zhang, J., Williams, M. S., Ou, J. "Hysteretic behavior of improved Pall-typed frictional dampers", Engineering Structures, 27(8), pp. 1258-1267, 2005.

https://doi.org/10.1016/j.engstruct.2005.03.010

[18] Sarjou, P. H., Shabakhty, N. "Effect of the improved Pall friction damper on the seismic response of steel frames", Engineering, Technology \& Applied Science Research, 7(4), pp.1833-1837, 2017. https://doi.org/10.48084/etasr.1176

[19] Fleck Fadel Miguel, L., Fleck Fadel Miguel, L., Lopez, R. H. "Simultaneous optimization of force and placement of friction dampers under seismic loading", Engineering Optimization, 48(4), pp. 582-602, 2016. https://doi.org/10.1080/0305215X.2015.1025774

[20] Nabid, N., Hajirasouliha, I., Petkovski, M. "A Practical Method for Optimum Seismic Design of Friction Wall Dampers", Earthquake Spectra, 33(3), pp. 1033-1052, 2017. https://doi.org/10.1193/110316eqs190m

[21] Nabid, N., Hajirasouli, I., Petrovski, M. "Simplified Method for Optimal Design of Friction damper Slip Loads by Considering Near-Field and Far-Field Ground Motions", Journal of Earthquake Engineering, 25(9), pp. 1851-1875, 2021. https://doi.org/10.1080/13632469.2019.1605316 
[22] Esmaeilzad, A., Khanlari, K. "Dynamic condensation of non-classically damped structures using the method of Maclaurin expansion of the frequency response function in Laplace domain", Journal of Sound and Vibration, 426(9), pp. 111-128, 2018. https://doi.org/10.1016/j.jsv.2018.04.016

[23] Logan, D. L. "A first Course in the Finite Element Method, Rahul Print O Pack", Dehli, India, 2007.

[24] Chopra, A. K. "Dynamics of structures: Theory and Applications to Earthquake Engineering", Prentice-Hall, Des Moines, IA, USA, 1995. https://oi.org/10.1007/BF00426980

[25] Butcher, J. C. "A history of Runge Kutta method", Applied Numerical Mathematics, 20(3), pp. 247-260, 1996. https://doi.org/10.1016/0168-9274(95)00108-5

[26] Lee, S.-H., Park, J.-H., Lee, S.-K., Min, K.-W. "Allocation and slip load of friction dampers for a seismically excited building structure based on story shear force distribution", Engineering Structures, 30(4), pp. 930-940, 2008.

https://doi.org/10.1016/j.engstruct.2007.03.020

[27] Fallah, N., Honarparst, S. "NSGA-II based multi objective optimization in design of pall friction dampers", Journal of Constructional Steel Research, 89, pp. 75-85, 2013.

https://doi.org/10.1016/j.jcsr.2013.06.008
[28] Feliciano, C. "Design optimization for plane structures equipped with friction dampers", MS Thesis, Instituto Superior Técnico, University of Lisbon, 2015.

[29] Fleck Fadel Miguel, L., Fleck Fadel Miguel, L., Lopez, R. H. "Methodology for the simultaneous optimization of location and parameters of friction dampers in the frequency domain", Engineering Optimization, 50(12), pp. 2108-2122, 2018. https://doi.org/10.1080/0305215X.2018.1428318

[30] Sanghai, S., Pawade, P. "Optimal placement of friction dampers in building using considering nonlinearity of soil", Innovative Infrastructure Solutions, 6(28), Article number: 28, 2021. https://doi.org/10.1007/s41062-020-00395-8

[31] Kim, J., An, S. "Optimal distribution of friction dampers for seismic retrofit of a reinforced concrete moment frame", Advances in Structural Engineering, 20(10), pp. 1523-1539, 2016. https://doi.org/10.1177/1369433216683197

[32] Ontiveros-Pérez, S. P., Fleck Fadel Miguel, L., Fleck Fadel Miguel, L. "Optimization of location and forces of friction dampers", REM International Engineering Journal, 70(3), pp. 273-279, 2017. https://doi.org/10.1590/0370-44672015700065 